\title{
SYNTHESIS, CHARACTERIZATION AND ADSORPTION STUDIES OF PHOSPHORYLATED CELLULOSE FOR THE RECOVERY OF LITHIUM FROM AQUEOUS SOLUTIONS
}

\author{
YAŞAR KEMAL RECEPOĞLU* and ASLI YÜKSEL ${ }^{* * * *}$ \\ *Department of Chemical Engineering, Izmir Institute of Technology, \\ 35430, Urla, Izmir, Turkey \\ ${ }^{* *}$ Geothermal Energy Research and Application Center (GEOCEN), Izmir Institute of Technology, \\ 35430, Urla, Izmir, Turkey \\ \Corresponding author: Asli Yüksel, asliyuksel@iyte.edu.tr
}

Received October 7, 2020

In this study, pristine cellulose was functionalized by the phosphorylation reaction to make it suitable for lithium separation. After characterization studies of the synthesized adsorbent with SEM, EDX, FTIR, TGA and XPS, the effects of various parameters on the lithium uptake capacity of the adsorbent were examined. The analysis of equilibrium data by several adsorption models showed that maximum adsorption capacity of the adsorbent was found to be $9.60 \mathrm{mg} / \mathrm{g}$ at $25^{\circ} \mathrm{C}$ by the Langmuir model. As initial concentration and contact time increased, adsorption capacity also increased, however, mild temperature $\left(25-35^{\circ} \mathrm{C}\right)$ and $\mathrm{pH}(5-6)$ were better for the adsorption of lithium. $80 \%$ of lithium adsorption within three minutes proved the fast kinetic nature of the adsorbent. A $99.5 \%$ desorption efficiency of lithium was achieved with $0.5 \mathrm{M} \mathrm{H}_{2} \mathrm{SO}_{4}$, among $\mathrm{HCl}$ and $\mathrm{NaCl}$ with different molarities. Phosphorylated cellulose was shown to be a favorable adsorbent for the recovery of lithium from aqueous solutions.

Keywords: adsorption, cellulose, isotherm, lithium, phosphorylation

\section{INTRODUCTION}

Lithium has been recognized as an important raw material in the last decade due to its wide use in many applications, such as rechargeable batteries (market share: 35\%), glasses and ceramics (market share: 32\%), light aircraft alloys, medicinal drugs, thermonuclear fusion, air purification, electrode welding paints, additives for lubricating greases and cement. ${ }^{1,2}$ Especially since the 1990s, large battery applications in lithium ion batteries, such as electric vehicles and stationary storage systems, have gained significance in terms of continuous improvement, cost and energy savings. ${ }^{3}$ Therefore, there is a growing interest in lithium and lithium sources worldwide. Also, it has been noted that the recovery of lithium from several saline waters, such as geothermal water and seawater, which are known to be large sources of lithium, is less costly than its recovery from rocks as a result of mining. ${ }^{4-6}$ Apart from technologies such as solvent extraction, ${ }^{7,8}$ solar evaporation, ${ }^{9}$ coprecipitation, ${ }^{10}$ and membrane processes, ${ }^{11,12}$ adsorption and/or ion exchange methods with lower operating costs can be considered as the most suitable methods for the recovery of lithium from diluted aqueous sources. Some inorganic ion exchange materials with superior physicochemical properties (e.g., large specific surface area, high adsorption and ion exchange capacity, mechanical stability, and layer structure) exhibit extremely high selectivity for lithium ions. Various studies have been carried out for the recovery of lithium from seawater using different types of inorganic adsorbents. ${ }^{13-18}$ Among these adsorbents, $\lambda-\mathrm{MnO}_{2}$ adsorbent is the most studied one. . $^{515-25}$

The synthesis and development of novel functional low-cost adsorbents with large capacity, high selectivity, as well as high adsorption rate, still greatly attract interest for both the removal of hazardous materials and the recovery of valuable minerals from water. Specifically, adsorbents derived from a natural polymer are the most preferable ones due to their 
being environmentally benign materials. ${ }^{26}$ Cellulose is the most widely available natural polymer that accounts for about $35-50 \%$ of the plant materials in the world. ${ }^{27}$ It is a linear syndiotactic homopolymer composed of Danhydroglucopyranose units (AGU), which are linked together by $\beta$ - $(1 \rightarrow 4)$-glucosidic bonds. The hydroxyl groups at both ends of the cellulose chain behave differently. Bridging and ring oxygen atoms are mainly involved in intermolecular and intra-molecular interactions, such as hydrogen bonding and degradation reactions. $^{28}$

Zhou et al. $^{29}$ used glycidyl methacrylate and sulfosalicylic acid to modify cellulose and obtained a new adsorbent CGS (i.e., cellulose modified with glycidyl methacrylate and sulfosalicylic acid) for the removal of crystal violet $(\mathrm{CV})$. So far, Yue et al. ${ }^{30}$ synthesized and characterized a cellulose based adsorbent prepared by grafting amino-terminated hyperbranched polymer $\left(\mathrm{NH}_{2}-\mathrm{HBP}\right)$ and betacyclodextrin $(\beta-C D)$ onto cotton fibers for the removal of anionic and cationic dyes. In addition to the removal of textile dyes, cellulose-based adsorbents synthesized by different esterification methods for cellulose modification, using various chemical reagents and pollutant binding groups for the removal of different heavy metals, were also reported in the literature. ${ }^{31-43}$ Phosphorylation is one of the modification ways for cellulose. The grafting reaction of phosphorus compounds to cellulose can be carried out by several routes: with trivalent (III) or pentavalent (V) phosphorus reagents, by direct or indirect bonding of phosphorus functions to cellulose, using cellulose or cellulose derivatives as substrates, with or without catalysts, in heterogeneous or homogeneous reaction environment, etc. Phosphorus derivatives, such as $\mathrm{POCl}_{3}, \mathrm{H}_{3} \mathrm{PO}_{4}$, and $\mathrm{P}_{2} \mathrm{O}_{5}$, are the most utilized phosphorylating agents for pentavalent phosphorus. These reagents, usually leading to anionic cellulose phosphates, show lower esterification reactivity than the similar derivatives of trivalent phosphorus and cause higher degradation of the cellulose substrate. This drawback is partially overcome if urea is introduced in the phosphorylation system as a catalyst. $^{44,45}$ Phosphate groups are known to show excellent chelating properties. Thus, phosphated polysaccharides were used as metal-chelating polymers, as cation exchange materials and for the treatment of polluted wastewater. ${ }^{46}$ For example, phosphated chitosan and cellulose were used as adsorbents for uranium or for various transition metals and lanthanide ions. ${ }^{47,48}$ On the other hand, novel functionalized cellulose microspheres have also been developed by different synthesis routes and functional groups for efficient lithium ion separation. Chen et al. ${ }^{49}$ recently synthesized cellulose-based microspheres containing crown ether groups (named as MCMg-AB15C5) by pre-irradiation-induced emulsion grafting of glycidyl methacrylate (GMA), followed by the chemical reaction between the epoxy group of grafted polymer and 4'aminobenzo-15-crown-5 (AB15C5), which showed maximum adsorption capacity of 12.9 $\mathrm{mg} / \mathrm{g}$. Another cellulose microsphere adsorbent with sulfonic acid groups (named as CGS) was prepared by the pre-irradiation-induced emulsion graft polymerization of glycidyl methacrylate onto cellulose microspheres through subsequent sulfonation and protonation, which exhibited adsorption capacity of $16.0 \mathrm{mg} \mathrm{Li}^{+} / \mathrm{g}$-adsorbent. ${ }^{50}$ Tang et $a l .^{51}$ developed and investigated a renewable and recyclable hydrogen manganese oxide (HMO)-modified cellulose film toward the extraction of lithium from lithium-containing aqueous solutions. They found that the HMO/cellulose film exhibited a higher $\mathrm{Li}^{+}$ adsorption capacity (21.6 mg/g HMO) than the HMO/polymer (e.g., poly(vinyl chloride) or poly(vinylidene fluoride)) films.

In this paper, we aimed to obtain a low-cost and novel lithium selective adsorbent by attaching phosphorous functional groups to pristine cellulose. To the best of our knowledge, no studies have been reported in the literature regarding the synthesis of lithium selective adsorbents from cellulose. Recently, Çiçek et al. ${ }^{52}$ studied the lithium selectivity of this functional group using chelating resins containing aminomethylphosphonic acid for lithium removal from water. Moreover, Suflet et $a{ }^{28}{ }^{28}$ pioneered the synthesis and characterization of phosphorylated cellulose by reacting microcrystalline cellulose in molten urea with phosphoric acid. ${ }^{45}$ The synthesized functional adsorbent was characterized and evaluated for its potential to recover lithium from aqueous solution in terms of various parameters, such as adsorbent dosage, initial concentration of $\mathrm{Li}$, contact time, temperature, $\mathrm{pH}$ and common ion. The isotherm of the adsorption process was studied using Freundlich, Halsey, Langmuir, Redlich-Peterson and Temkin models. Thermodynamic parameters 
were calculated, and desorption of lithium was achieved successfully. The adsorbent exhibited quite rapid sorption of lithium.

\section{EXPERIMENTAL}

\section{Materials}

Microcrystalline cellulose, di-Ammonium hydrogen phosphate, hydrochloric acid (37\%), lithium chloride, ortho-phosphoric acid (85\%), potassium chloride, sodium chloride, sodium hydroxide, sulfuric acid $(95-97 \%)$ and urea were purchased from Merck. Other reagents were all of analytical grade.

\section{Synthesis of the adsorbent}

\section{Conditioning of the cellulose}

In order to activate hydroxy groups in cellulose prior to the phosphorylation reaction (that is, the $\mathrm{NaOH}$ treatment breaks the van der Waals and hydrogen bonds between cellulose molecules, which causes more hydroxy groups to become exposed to $\mathrm{H}_{3} \mathrm{PO}_{4}$ in the second step of the process) as reported in the patent,${ }^{53} 10 \mathrm{M} \mathrm{NaOH}$ solution $(100 \mathrm{~mL})$ was added to microcrystalline cellulose $(10 \mathrm{~g})$ and the mixture was stirred at room temperature $\left(25^{\circ} \mathrm{C}\right)$ for $2 \mathrm{~h}$. Then, $10 \mathrm{M} \mathrm{HCl}(100 \mathrm{~mL})$ was added to the mixture to neutralize the solution and to precipitate cellulose. After that, the mixture was washed with excess water and filtered to remove the alkali. Finally, the residue was dried at $70{ }^{\circ} \mathrm{C}$ for $6 \mathrm{~h}$ and was ground in a mortar and pestle.

\section{Binding of functional groups to cellulose} (phosphorylation reaction)

The phosphorylating chemical solution prepared by dissolving phosphoric acid $(0.15 \mathrm{~mol})$, diammonium hydrogen phosphate $(0.2 \mathrm{~mol})$ and urea $(1 \mathrm{~mol})$ in water $(150 \mathrm{~mL})$ was added to previously $\mathrm{NaOH}$ treated cellulose $(10 \mathrm{~g})$. After thoroughly mixing the mixture thus prepared, it was allowed to stand at room temperature $\left(25{ }^{\circ} \mathrm{C}\right)$ for $1 \mathrm{~h}$, and next, the water content was evaporated, and the residue completely dried at $105{ }^{\circ} \mathrm{C}$ for $18 \mathrm{~h}$. The mixture was then heated to $150{ }^{\circ} \mathrm{C}$ and it was allowed to react at this temperature for $2 \mathrm{~h}$ based on the reaction mechanism given below in Figure 1. After that, the reaction product was washed with excess water and dried at 70 ${ }^{\circ} \mathrm{C}$ for $6 \mathrm{~h}$ and finally was ground in a mill to give functionalized cellulose. ${ }^{53}$

\section{Characterization of the synthesized adsorbent}

The surface morphology of the materials was examined by SEM equipment (Quanta 250 SEM). Before taking SEM photomicrographs at an accelerating voltage range of 3.0-5.0 kV, the free surfaces of the materials were coated with thin layers of gold. The elemental analysis obtained by EDX combined with the SEM method gave information on whether the expected functional groups were effectively attached to the cellulose matrix, or not.

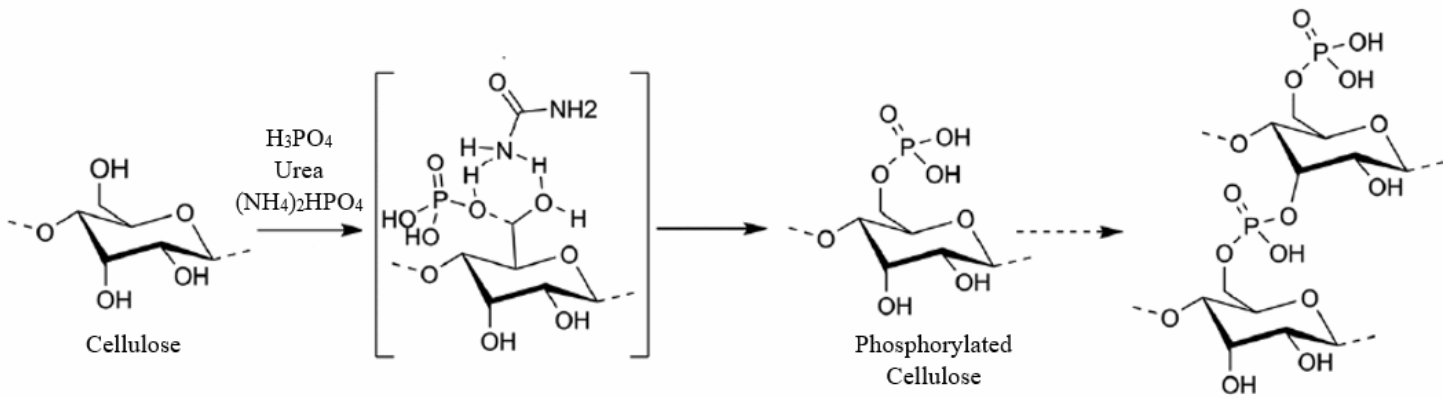

Figure 1: Proposed mechanism for cellulose phosphorylation with $\mathrm{H}_{3} \mathrm{PO}_{4}$ in the presence of urea

A Shimazdzu FTIR-8400S spectrophotometer was used to record the changes in the bond structures of pristine cellulose and phosphorylated functional cellulose by IR spectra within the range of 4000-400 $\mathrm{cm}^{-1}$, with a resolution of $4 \mathrm{~cm}^{-1}$ and 24 scans per sample. The IR spectra were recorded in a solid state using the $\mathrm{KBr}$ pellet method, in which pellets of ca. 2 $\mathrm{mg}$ of cellulosic samples were prepared by mixing with ca. $150 \mathrm{mg}$ of spectroscopic grade $\mathrm{KBr}$.

The measurable differences in the thermal stability and heat capacity of pristine and phosphorylated materials were determined by TGA equipment (Setaram). Thermograms were obtained by heating the samples from $30{ }^{\circ} \mathrm{C}$ to $1000{ }^{\circ} \mathrm{C}$, in a dynamic heating regime, under nitrogen with a constant heating rate of $5{ }^{\circ} \mathrm{C} / \mathrm{min}$.

Quantitative elemental analysis was performed by XPS (Thermo Scientific, Nexsa) having $180^{\circ}$ hemispherical analyzer-128 channel detector for $\mathrm{C}, \mathrm{O}$, $\mathrm{P}$ and $\mathrm{Li}$ elements based on the changes in the bond energies in the molecule. The elements were scanned in the range of $0.0-1350.0 \mathrm{eV}$, using monochromatic $\mathrm{Al} \mathrm{K} \alpha \mathrm{X}$-rays $(1486.68 \mathrm{eV})$, with a pass energy of 30 $\mathrm{eV}$ and scan number of 3 .

\section{Batch adsorption experiments}

A series of experiments were performed to determine the lithium adsorption performance of 
YAŞAR KEMAL RECEPOĞLU and ASLI YÜKSEL

phosphorylated functional cellulose in model $\mathrm{Li}$ solution, based on preliminary studies of lithium adsorption, showing that $24 \mathrm{~h}$ is adequate to reach adsorption equilibrium for batch treatment. To observe the effect of adsorbent dosage, various amounts (0.1$0.5 \mathrm{~g}$ ) of phosphorylated functional cellulose were placed in plastic bottles that contained $25 \mathrm{~mL}$ of $\mathrm{LiCl}$ solution $\left(\mathrm{Li}^{+}\right.$: $\left.10 \mathrm{mg} \mathrm{L}^{-1}\right)$ at different mass/volume ratios, and the solutions were shaken at ambient temperature $\left(25^{\circ} \mathrm{C}\right)$ at $180 \mathrm{rpm}$. The effects of the initial concentration of lithium ions and temperature on the adsorption process were determined via $\mathrm{LiCl}$ solution $(25 \mathrm{~mL})$ at various concentrations $(10-100 \mathrm{mg}$ $\left.\mathrm{L}^{-1}\right)$ and a constant mass of phosphorylated functional cellulose $(0.3 \mathrm{~g})$, under shaking at various temperatures $\left(25,35,45\right.$ and $\left.55{ }^{\circ} \mathrm{C}\right)$. For the effect of $\mathrm{pH}$, experiments were carried out at various $\mathrm{pH}$ values (26) using $\mathrm{LiCl}$ solution $\left(\mathrm{Li}^{+}: 10 \mathrm{mg} \mathrm{L}^{-1}\right)$ and $0.3 \mathrm{~g}$ of phosphorylated functional cellulose at $25{ }^{\circ} \mathrm{C}$. The selectivity of the phosphorylated functional cellulose was investigated using $25 \mathrm{~mL}$ of the adjusted model solution $\left(\mathrm{Li}^{+}, \mathrm{K}^{+}\right.$and $\mathrm{Na}^{+}$each $\left.10 \mathrm{mg} \mathrm{L}{ }^{-1}\right)$ at ambient temperature as well. All the experiments were repeated twice, and average values were reported with error bars as standard deviation.

The adsorption capacity and recovery percentage of $\mathrm{Li}$ were calculated by the following equations, respectively:

$q_{e}=\frac{\left(C_{0}-C_{e}\right) V}{m}$

$R=\frac{C_{0}-C_{e}}{C_{0}} \times 100$

where $q_{e}$ is the unit adsorption capacity at equilibrium $(\mathrm{mg} / \mathrm{g}), R$ is the recovery percentage of $\mathrm{Li}, C_{0}$ and $C_{e}$ are the initial $\mathrm{Li}$ concentration $(\mathrm{mg} / \mathrm{L})$ and $\mathrm{Li}$ concentration at equilibrium $(\mathrm{mg} / \mathrm{L})$, respectively. $V$ is the volume of Li solution (L), and $m$ is the dry weight of the adsorbent $(\mathrm{g})$.

\section{Adsorption kinetics}

For kinetic tests, the adsorbents with various dosages (3.0-5.0 g/L) were contacted with $750 \mathrm{~mL}$ of $10 \mathrm{mg} \mathrm{L}^{-1} \mathrm{Li}$ containing solution at $25{ }^{\circ} \mathrm{C}$. To investigate the effect of contact time on the recovery of lithium, sampling was done periodically in the time interval of $0-120 \mathrm{~min}$.

\section{Desorption and regeneration of the phosphorylated functional cellulose}

Saturated adsorbents obtained from the adsorption experiment via $100 \mathrm{mg} \mathrm{L}^{-1} \mathrm{Li}^{+}$and $10 \mathrm{~g} / \mathrm{L}$ adsorbent dosage were regenerated using $0.5 \mathrm{M}, 1.0 \mathrm{M}$ and $2.0 \mathrm{M}$ of $\mathrm{NaCl}, \mathrm{HCl}$ and $\mathrm{H}_{2} \mathrm{SO}_{4}$ as regenerants by $25 \mathrm{~mL}$ solvent $/ 0.3 \mathrm{~g}$ solid ratio and at $25{ }^{\circ} \mathrm{C}$, similarly to the method applied in the batch lithium adsorption experiments. After regeneration, concentrated Li can be recovered by evaporation of the spent solution in $\mathrm{Li}$ salt forms and further purification steps can be considered.

\section{Analysis of Li and other cations}

After each experiment, the adsorbents were separated from the solution by filtration. The filtrate was diluted as necessary and the concentrations of cations in the filtrate were determined by an ICP-OES instrument (Agilent Technologies, 5110).

\section{THEORETICAL BACKGROUND Adsorption isotherms}

Equilibrium data were analyzed by the Freundlich, Halsey, Langmuir, Redlich-Peterson and Temkin models using the non-linear regression technique.

The Langmuir theory assumes that adsorption occurs at specific homogeneous sites inside the adsorbent and that once a lithium ion occupies a site, no additional adsorption can occur there. In other words, there is no transmigration of adsorbate in the plane of the surface, resulting in uniform energies of adsorption onto the surface. ${ }^{54,55}$ The Langmuir model ${ }^{56}$ is expressed as follows:

$q_{e}=\frac{Q_{\max } K_{L} C_{e}}{1+K_{L} C_{e}}$

where $\mathrm{Q}_{\max }(\mathrm{mg} / \mathrm{g})$ is the maximum adsorption capacity and $\mathrm{K}_{\mathrm{L}}(\mathrm{L} / \mathrm{mg})$ is the Langmuir constant related to the affinity of the binding sites.

The essential characteristics of the Langmuir isotherm is also expressed by a dimensionless constant called equilibrium parameter or separation factor, $\mathrm{R}_{\mathrm{L}}$, as: ${ }^{57}$

$R_{L}=\frac{1}{1+K_{L} C_{0}}$

The parameter $\mathrm{R}_{\mathrm{L}}$ describes the shape of the isotherm as follows:

- $\mathrm{R}_{\mathrm{L}}=0$ irreversible,

- $0<\mathrm{R}_{\mathrm{L}}<1$ favorable,

- $\mathrm{R}_{\mathrm{L}}=1$ linear,

- $\mathrm{R}_{\mathrm{L}}>1$ unfavorable.

The Freundlich model is an exponential equation assuming that as the adsorbate concentration increases, the concentration of the adsorbate on the adsorbent surface also increases. According to this theory, the stronger binding sites are occupied first, and the binding strength decreases with an increasing degree of site occupation, corresponding to sorption on heterogeneous surfaces or surfaces supporting sites of varied affinities. ${ }^{54,57}$ The Freundlich model is given as follows: ${ }^{58}$

$q_{e}=K_{F} C_{e}^{1 / n}$

where $\mathrm{K}_{\mathrm{F}}\left((\mathrm{mg} / \mathrm{g})(\mathrm{L} / \mathrm{mg})^{1 / \mathrm{n}}\right)$ and $n$ are Freundlich constants for adsorption capacity and adsorption intensity of the adsorbent, respectively. The value of $n$ also describes the adsorption characteristics as follows:

- $\mathrm{n}<1$ unfavorable adsorption, 
- $\mathrm{n}=1$ no interaction between the adsorbed species means homogenous adsorption,

- $\mathrm{n}>1$ favorable adsorption.

The Redlich-Peterson (R-P) model compromises between the Freundlich and Langmuir systems. This three-parameter model has the advantages of both models. ${ }^{57}$ The R-P model ${ }^{59}$ is represented as follows:

$q_{e}=\frac{K_{R P} C_{e}}{1+\left(\alpha C_{e}\right)^{\beta}}$

where $\mathrm{K}_{\mathrm{RP}}(\mathrm{L} / \mathrm{mg})$ and $\boldsymbol{\alpha}(\mathrm{L} / \mathrm{mg})^{\beta}$ are $\mathrm{R}-\mathrm{P}$ isotherm constants, whereas $\beta$ is the exponent which lies between 0 and 1 . The $\mathrm{R}-\mathrm{P}$ model has two limiting cases, when $\beta=0$, the $\mathrm{R}-\mathrm{P}$ model transforms to Henry's law equation, whereas when $\beta=1$, the Langmuir model results.

The Temkin isotherm considers explicitly the adsorbent-adsorbate interactions by a factor. Due to these interactions, the heat of adsorption of all the molecules in the layer decreases linearly as coverage increases. $^{57}$ The Temkin model $^{60}$ is expressed as follows:

$q_{e}=\left(R T / b_{T}\right) \ln \left(A C_{e}\right)$

where $\mathrm{B}=\mathrm{RT} / \mathrm{b}_{\mathrm{T}}$, which is the Temkin constant related to the heat of sorption, whereas $A(\mathrm{~L} / \mathrm{mg})$ is the equilibrium binding constant related to the maximum binding energy. $R(8.314 \mathrm{~J} / \mathrm{mol} \mathrm{K})$ is the universal gas constant and $T(\mathrm{~K})$ is the absolute solution temperature.

The Halsey isotherm is used to evaluate multilayer adsorption at a relatively large distance from the surface and this model verifies the heteroporous nature of the adsorbent. ${ }^{61}$ The Halsey model ${ }^{62}$ can be defined as:

$q_{e}=\exp \left(\frac{\ln K_{H}-\ln C_{e}}{n_{H}}\right)$

where $\mathrm{K}_{\mathrm{H}}$ and $\mathrm{n}_{\mathrm{H}}$ are Halsey isotherm constants.

\section{Adsorption thermodynamics}

The effect of temperature on lithium adsorption onto the phosphorylated functional adsorbent was also explained in terms of thermodynamic parameters. In this context, adsorption thermodynamics means obtaining thermodynamic parameters, including free energy changes $\left(\Delta G^{\circ}\right)$, standard enthalpy changes $\left(\Delta \mathrm{H}^{\mathrm{o}}\right)$ and entropy changes $\left(\Delta \mathrm{S}^{\mathrm{o}}\right)$ associated with the adsorption process to deduce the adsorption mechanism. ${ }^{63}$

$\Delta \mathrm{G}^{\mathrm{o}}$ is the basic criterion of spontaneity. If the value of $\Delta \mathrm{G}^{\mathrm{o}}$ is negative, the reaction occurs spontaneously at the given temperature. The $\Delta \mathrm{G}^{0}$ value can be expressed by Equation (9) and the relationship between $\Delta \mathrm{G}^{\mathrm{o}}, \Delta \mathrm{H}^{\mathrm{o}}$ and $\Delta \mathrm{S}^{\mathrm{o}}$ by Equation (10):

$\Delta G^{\circ}=-R T \ln K_{e}$

$\Delta G^{\circ}=\Delta H^{\circ}-T \Delta S^{\circ}$

Other thermodynamic parameters $\left(\Delta \mathrm{H}^{\mathrm{o}}\right.$ and $\left.\Delta \mathrm{S}^{\circ}\right)$ of the adsorption process can be determined from Van't
Hoff's Equation (Eq. 11) by plotting $1 / \mathrm{T}$ versus $\ln \mathrm{K}_{\mathrm{e}}$ for different temperatures. ${ }^{63}$

$\ln K_{e}=-\frac{\Delta H^{\circ}}{R T}+\frac{\Delta S^{\circ}}{R}$

The equilibrium constant $\left(\mathrm{K}_{\mathrm{e}}\right)$ obtained in the isotherms (usually in $\mathrm{L} \mathrm{mg}^{-1}$ ) must become dimensionless before applying in the Van't Hoff equation. In this sense, Lima et al. ${ }^{64}$ recommended a conversion of the best fitted isotherm constant ( $\mathrm{K}_{\text {isotherm }}$ ) into the dimensionless $\mathrm{K}_{\mathrm{e}}$ as in Equation (12) described below:

$K_{e}=\frac{\left(1000 K_{\text {isotherm }} M W_{\text {adsorbate }}\right)[\text { Adsorbate }]^{0}}{\gamma}$

where $\gamma$ is the coefficient of activity (dimensionless), [Adsorbate $^{0}$ is the standard concentration of the adsorbate $\left(1 \mathrm{~mol} \mathrm{~L}^{-1}\right) . \mathrm{MW}_{\text {adsorbate }}$ is the molecular weight of the adsorbate $\left(\mathrm{g} \mathrm{mol}^{-1}\right) .1000$ stands for converting $\mathrm{L} \mathrm{mg}^{-1}$ into $\mathrm{L} \mathrm{g}^{-1}$.

\section{RESULTS AND DISCUSSION}

\section{Characterization of the synthesized adsorbent}

Figure 2 shows the SEM images of pristine cellulose, $\mathrm{NaOH}$ treated cellulose, phosphorylated functional cellulose and lithium-adsorbed phosphorylated functional cellulose, respectively, taken at 5000× magnification to observe the changes in the morphological structure of the materials.

The morphological structure of pristine cellulose (Fig. 2(a)) changes as it is processed, especially when compared to the lithium-selective adsorbent (Fig. 2(c)) obtained by the phosphorylation reaction. When the same magnification images are compared, it is seen that the $\mathrm{Li}$ adsorbed functional adsorbent (Fig. 2(d)) transforms to a more porous structure and pristine cellulose has a more fibrous structure. On the other hand, Figure 3 shows the elemental mapping of the phosphorylated functional adsorbent and the results of EDX.

As a result of mapping, it was observed that $\mathrm{P}$ (blue) element was homogeneously added to the structure of phosphorylated functional cellulose, as well as C (red) and $\mathrm{O}$ (green) elements, coming from the structure of pristine cellulose. The presence and distribution of the $\mathrm{P}$ element at the scanned point indicates that the functional group is homogeneously located throughout the material. In addition, the weight percentages of atoms $(37.98 \% \mathrm{C}, 52.58 \% \mathrm{O}$, and $9.44 \% \mathrm{P})$ from the elemental analysis with EDX showed that functionalization was also successful. 

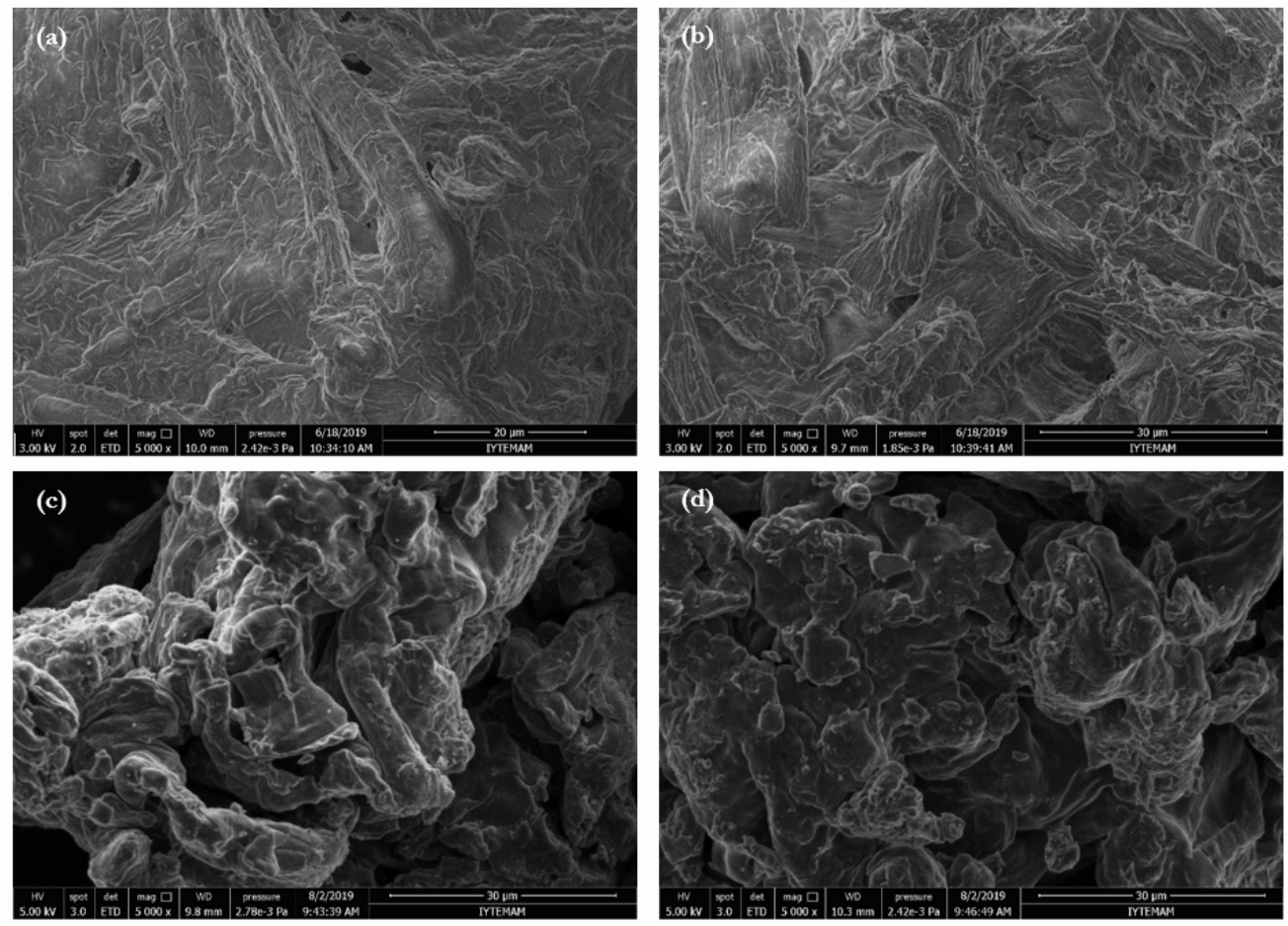

Figure 2: SEM images (magnification 5000x) of: (a) pristine cellulose, (b) $\mathrm{NaOH}$ treated cellulose, (c) phosphorylated cellulose and (d) lithium-loaded phosphorylated cellulose
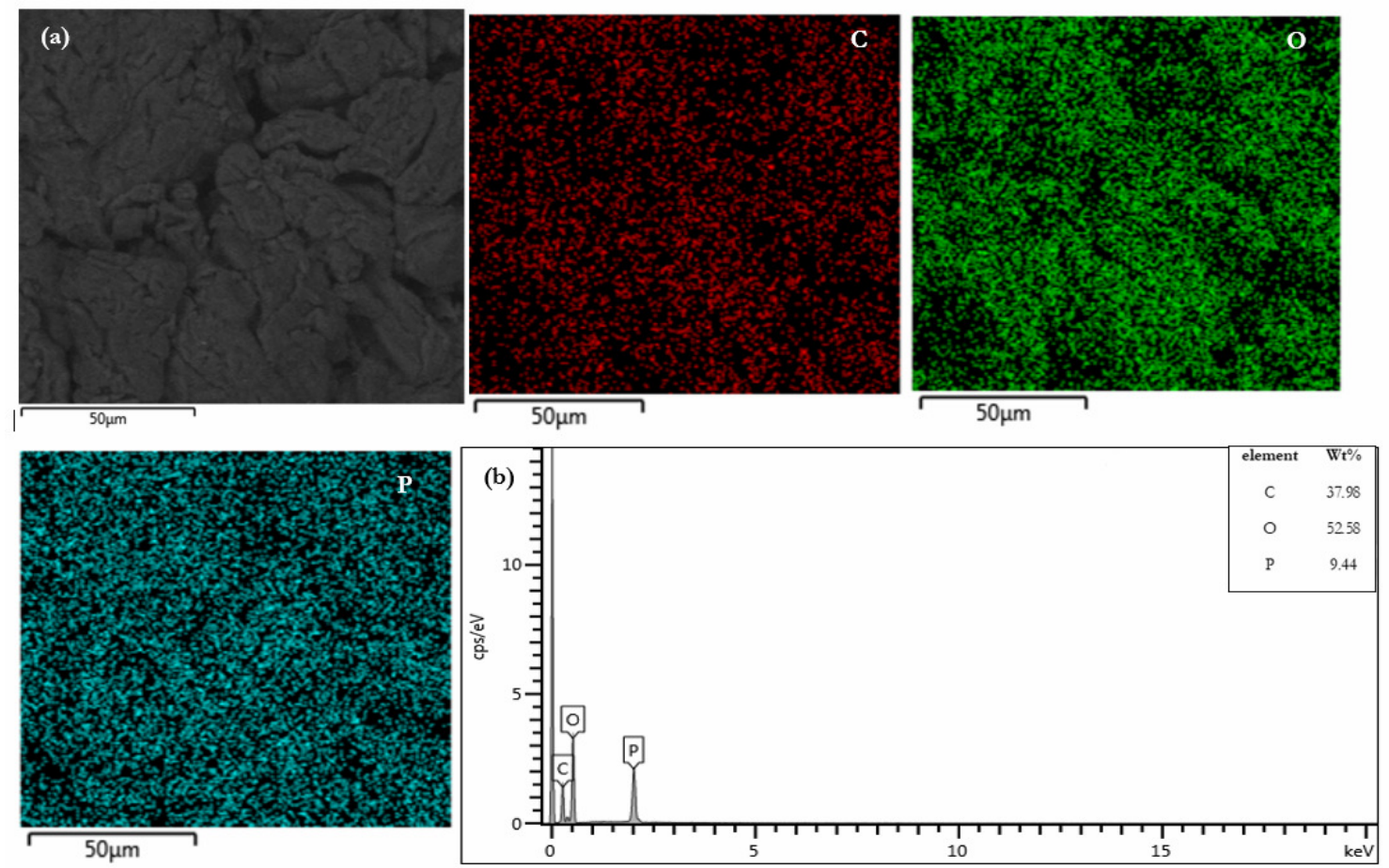

Figure 3: (a) C, $\mathrm{O}$ and $\mathrm{P}$ elemental mapping for phosphorylated cellulose; (b) EDX results 


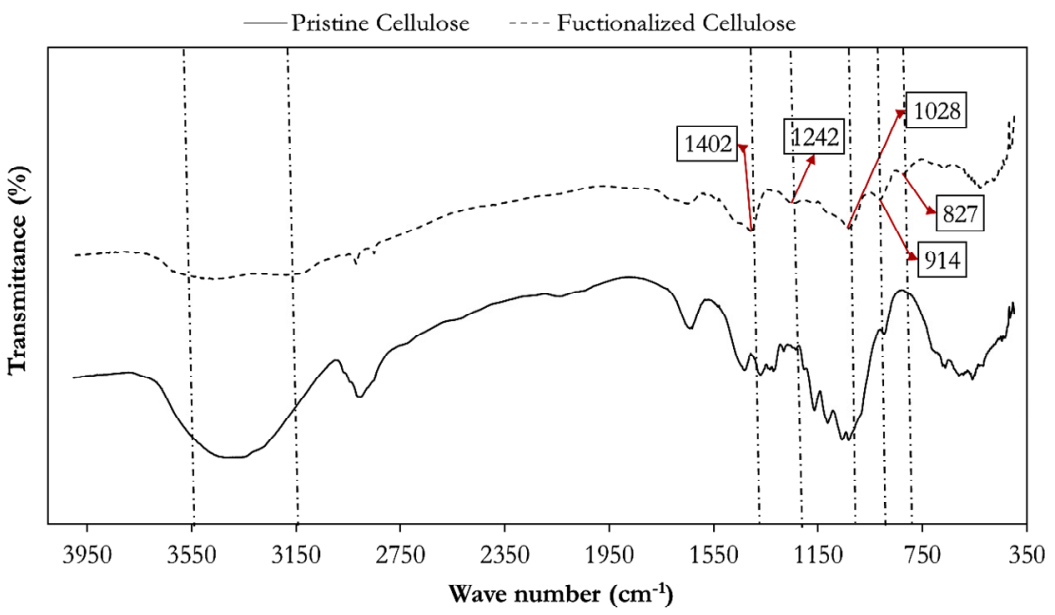

Figure 4: FT-IR spectra of pristine cellulose and phosphorylated cellulose

The FTIR spectra of pristine cellulose and phosphorylated functional cellulose-based adsorbent synthesized in this research are given in Figure 4 to compare the changes in the structure. In the literature, it is known that compounds containing the $\mathrm{P}-\mathrm{OH}$ group have a medium to strong wide band at $1040-910 \mathrm{~cm}^{-1}$ due to the $\mathrm{P}-\mathrm{O}$ stretching vibration. Therefore, the wavenumber seen around $1028 \mathrm{~cm}^{-1}$ indicates the presence of the $\mathrm{P}-\mathrm{O}$ bond. The band of $\mathrm{P}-\mathrm{O}-\mathrm{P}$ symmetric stretching vibrations is manifested in the interval $780-850 \mathrm{~cm}^{-1}$, so that the peak around $827 \mathrm{~cm}^{-1}$ verified the existence of this structure. However, the peak around $914 \mathrm{~cm}^{-1}$ showed the bands of $\mathrm{P}-$ $\mathrm{O}-\mathrm{P}$ antisymmetric stretching vibrations. It is also known that there is a strong $\mathrm{P}=\mathrm{O}$ bond in the range of $1350-1150 \mathrm{~cm}^{-1}$. The peak at ca. 1242 $\mathrm{cm}^{-1}$ is attributed to the presence of this structure. The $1402 \mathrm{~cm}^{-1}$ peak shows the presence of weak $\mathrm{OH}$ acid group. Moreover, in the range of 3200$3600 \mathrm{~cm}^{-1}$, the $\mathrm{OH}$ stretching vibration band became more asymmetric owing to the introduction of more acidic $\mathrm{OH}$ groups of phosphoric acids into the polymer. ${ }^{65,66}$ Hence, these peaks clearly revealed that the phosphorylated functional adsorbent has been successfully synthesized.

Figure 5 shows the thermogravimetric analysis (TGA) thermograms and differential weight loss thermograms (DTG) for pristine cellulose and phosphorylated functional cellulose. A minor weight loss of $1.32 \%$ around $100{ }^{\circ} \mathrm{C}$ in the graph of pristine cellulose could be attributed to the loss of adsorbed and bound water molecules. On the other hand, the major weight loss was $74.4 \%$ due to the decomposition of glycosidic bonds $(\mathrm{C}-\mathrm{O}-$ C) at about $368{ }^{\circ} \mathrm{C}$. At the final decomposition temperature, i.e. $1000{ }^{\circ} \mathrm{C}$, only $11.67 \mathrm{wt} \%$ of char remained. Compared to the unmodified pristine cellulose, the presence of phosphorus in the functional cellulose caused earlier dehydration of cellulose into char formation and a strong reduction in the decomposition temperature of cellulose. The $3.6 \%$ weight loss of functional cellulose at about $100{ }^{\circ} \mathrm{C}$ could be attributed to water molecules adsorbed by binding, as in the case of pristine cellulose. The initial weight loss thereafter was at around $200-250{ }^{\circ} \mathrm{C}$, and it is evident that the phosphoryl groups have increased the thermal decomposition reaction of the cellulosic polymer (and consequently the heat resistance of the material is reduced), but the carbonization (and hence flame resistance) has significantly increased instead. The weight loss of $38.1 \%$ at a temperature of about $870{ }^{\circ} \mathrm{C}$ indicates that the phosphorous functional group was decomposed, and it is known in the literature that cellulosic materials containing phosphoryl compounds have flame retardant properties. ${ }^{67}$ At the final decomposition temperature of the functional cellulose $\left(1000{ }^{\circ} \mathrm{C}\right), 55.4 \%$ by weight remained.

Figure 6 illustrates analyses of the survey scan, including the main atoms labelled on it. Since cellulose is a large molecule, $\mathrm{C} 1 \mathrm{~s}$ and $\mathrm{O} 1 \mathrm{~s}$ spectra were deconvoluted into several peaks. The peak at $134.21 \mathrm{eV}$, suggesting the new bond involving the atom $\mathrm{P}$, was observed for phosphorylated functional cellulose, in contrast to the pristine cellulose.

Estimating the local surface compositions of phosphorylated functional cellulose and the interactions of functional groups with loaded lithium is of high interest for understanding the 
YAŞAR KEMAL RECEPOĞLU and ASLI YÜKSEL

origins of its interesting separation property. Because the surface heterogeneities related to functionalized cellulose show little to no longrange structural order, diffraction-based techniques are generally not able to distinguish

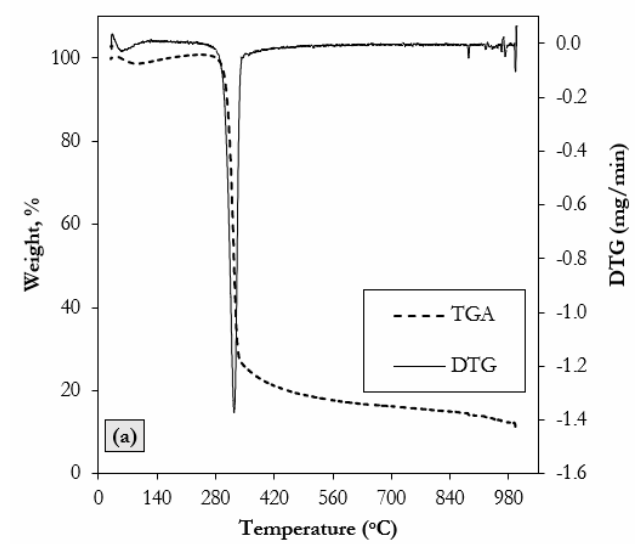

and identify surface functional groups. By comparison, analyses of the survey scan (Fig. 6) of lithium-loaded adsorbent enable near-surface elemental compositions of $\mathrm{C}, \mathrm{O}, \mathrm{P}$, and $\mathrm{Li}$ moieties to be determined.

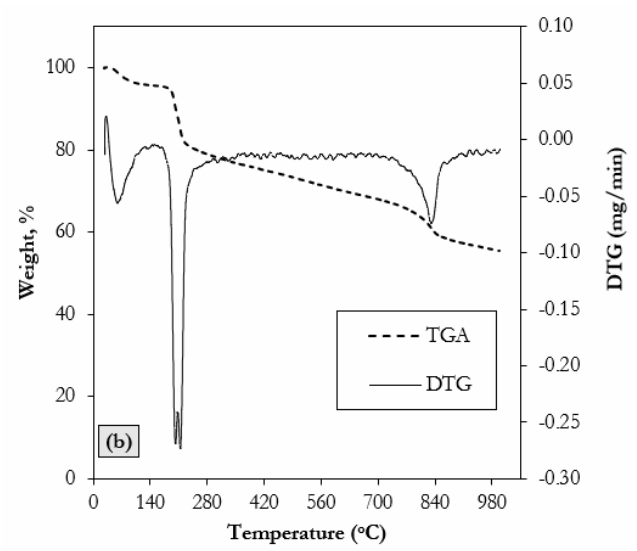

Figure 5: TGA and DTG thermograms of (a) pristine cellulose, and (b) phosphorylated functional cellulose
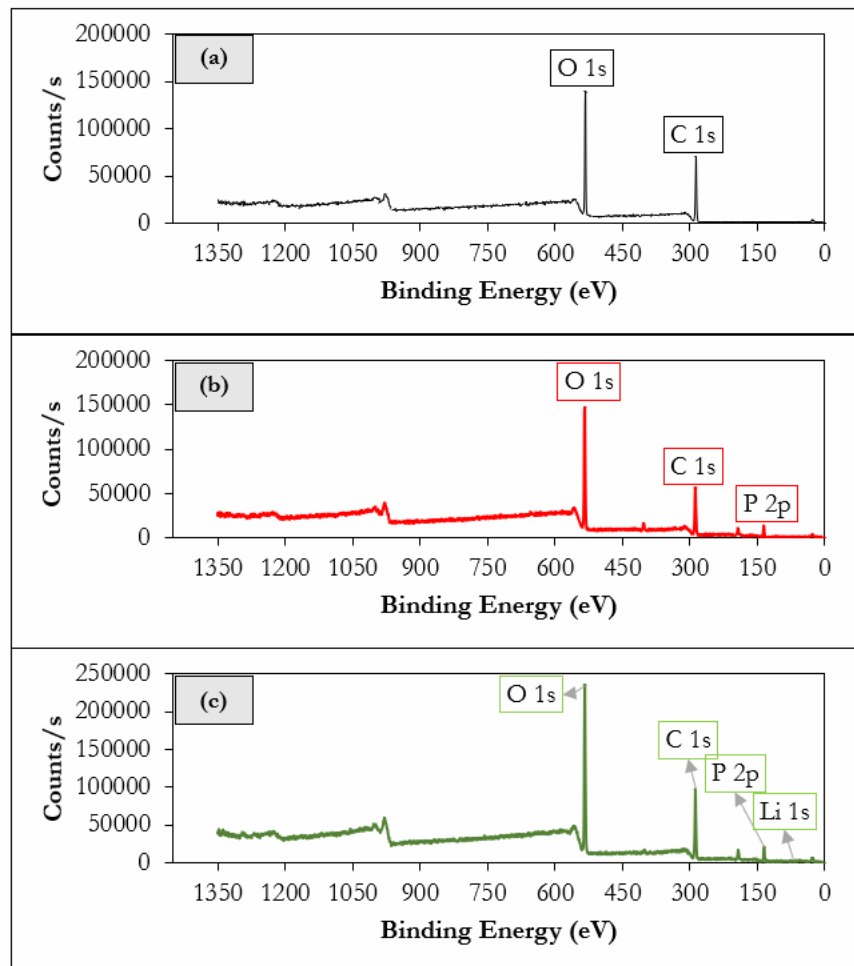

Figure 6: Analyses of survey scan for (a) pristine cellulose, (b) phosphorylated functional cellulose, and (c) lithium-loaded phosphorylated functional cellulose

There are no lithium secondary peaks to assist in confirmation and the Li1s peak has very low sensitivity. Therefore, it was difficult to confidently assign the Li1s peak to low concentrations. A large number of scans (50) was needed to acquire the Li1s spectrum. In a survey scan XPS spectrum of lithium loaded adsorbent, the signals at 287, 533, 134, and $55 \mathrm{eV}$ are 
attributed to the binding energies of $\mathrm{C} 1 \mathrm{~s}, \mathrm{O} 1 \mathrm{~s}, \mathrm{P}$ $2 \mathrm{p}$ and $\mathrm{Li} 1 \mathrm{~s}$ electrons, which can be better determined by the high resolution XPS spectra depicted in Figure 7. Spectral deconvolution of these signals yields near-surface elemental compositions of $\mathrm{C}, \mathrm{O}, \mathrm{P}$, and $\mathrm{Li}$ atoms, which were $43.63,43.32,6.63$ and 6.41 atom \%, respectively. According to the crosslinking structure of phosphorylated cellulose and its combined stoichiometry (Fig. 1), a P/Li atom ratio of approximately 1.03 obtained from XPS measurements is consistent with the structure, indicating the presence of these phosphorous moieties on the adsorbent surfaces because one $\mathrm{Li}^{+}$is exchanged with $\mathrm{H}^{+}$in the functional group and the expected ion exchange mechanism is given in Equation (13):

\section{Adsorption studies Effect of adsorbent dosage}

The adsorbent dosage is an important parameter to estimate the required amount of adsorbent for a specified initial concentration of adsorbate. ${ }^{68}$ The effect of adsorbent dosage on the lithium recovery by phosphorylated functional cellulose is shown in Figure 8. Adsorbent dosage was varied from 4.0 to $20.0 \mathrm{~g} \mathrm{~L}^{-1}$. The results showed that the lithium percentage separation increased with increasing adsorbent dosage due to increasing availability of functional sites.
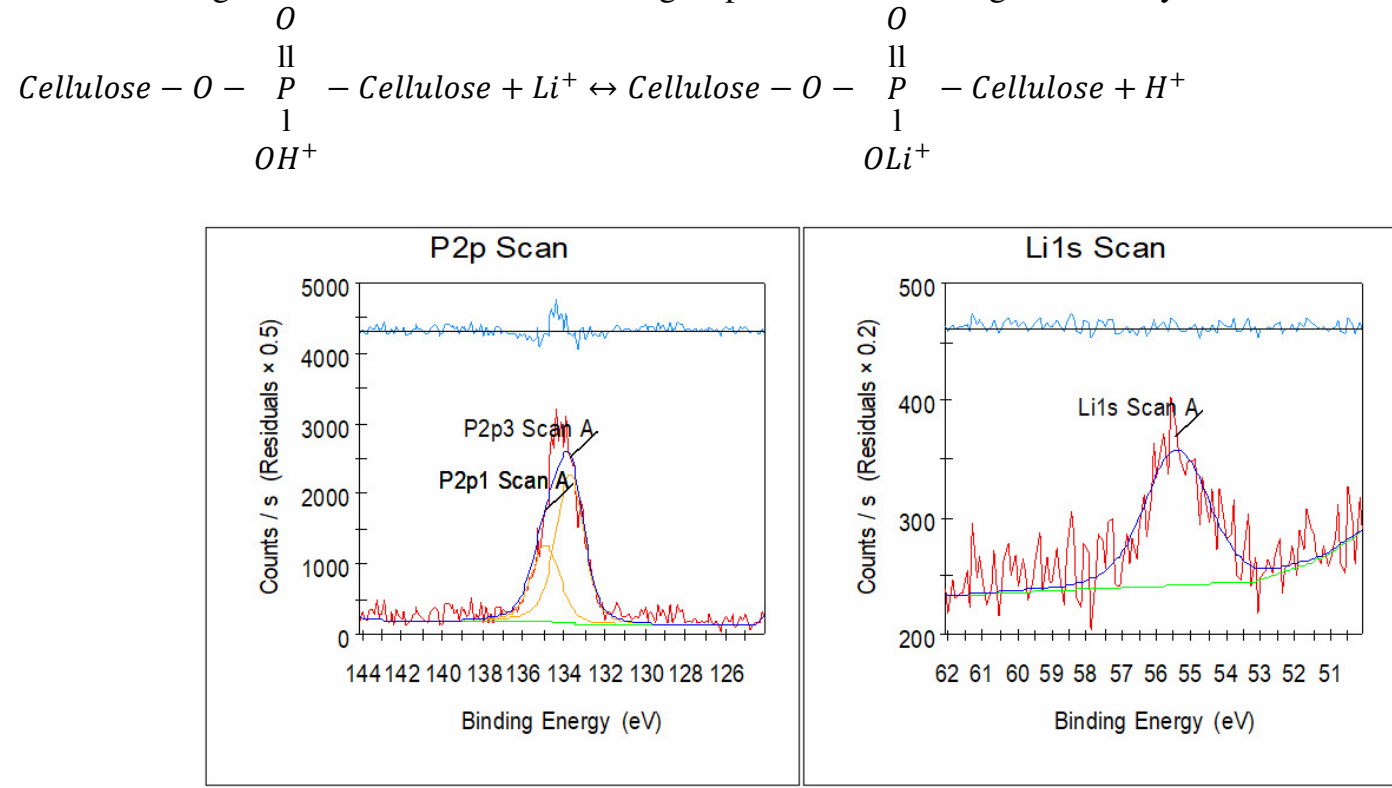

Figure 7: High-resolution XPS spectra acquired at room temperature for lithium-loaded phosphorylated functional cellulose with binding energies (BE, eV) that correspond to $\mathrm{P} 2 \mathrm{p}$ and $\mathrm{Li}$ 1s electrons

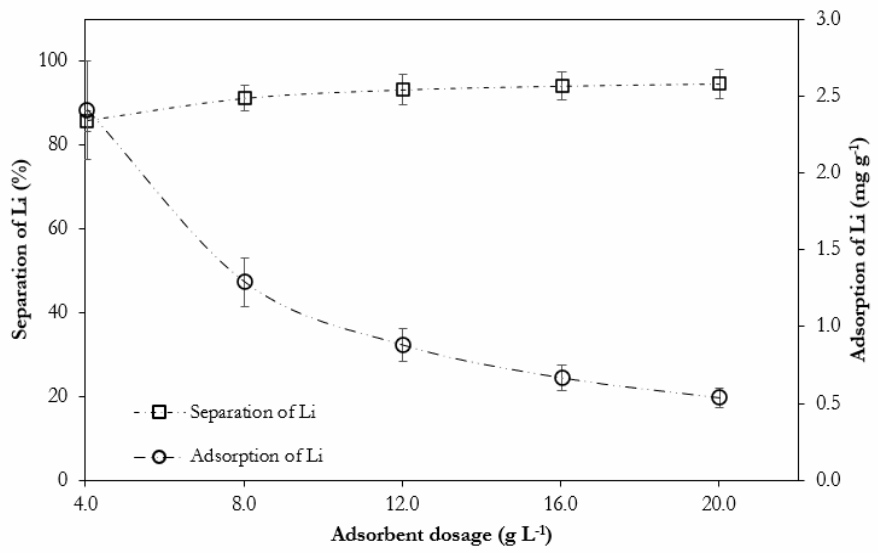

Figure 8: Dependence of lithium adsorption on the amount of adsorbent

$$
\left(\mathrm{C}_{0}=10 \mathrm{mgL}^{-1}, \mathrm{~T}=25^{\circ} \mathrm{C} \text { and } \mathrm{pH}=5-6\right)
$$


The maximum static adsorption of lithium onto phosphorylated functional cellulose was achieved for an adsorbent-to-solution ratio of 4.0 $\mathrm{g} \mathrm{L}^{-1}$ and was found to be ca. $2.50 \mathrm{mg} \mathrm{g}^{-1}$ for 10 $\mathrm{mg} \mathrm{L}^{-1}$ of initial solution concentration. The optimum adsorbent dosage of $12.0 \mathrm{~g} \mathrm{~L}^{-1}$ was obtained for ca. $94 \%$ of lithium separation, in which above $12.0 \mathrm{~g} / \mathrm{L}$ adsorbent dosage, the sorption equilibrium for lithium was reached and no further considerable increase was observed beyond this point as maximum removal was achieved. Therefore, the adsorbent dosage of 12.0 $\mathrm{g} / \mathrm{L}$ was chosen for subsequent experiments.

\section{Effect of pH}

$\mathrm{pH}$ plays a significant role on the adsorption of any substance depending on both the chemistry of adsorbate and the functional group attached to the matrix. The adsorbent in the present work contains the phosphoric acid group, which is triprotic, meaning that it has three acidic protons available to donate, with $p K a$ values of $2.16,7.21$ and 12.32, respectively. The separation of lithium from aqueous solution with $\mathrm{pH}$ ranging from 2 to 6 by adsorption onto phosphorylated functional cellulose is illustrated in Figure 9. Relatively less separation was observed at $\mathrm{pH} 2$ as expected. However, as initial $\mathrm{pH}$ increased up to 6 , the separation efficiency of lithium reached about $90 \%$ under specified conditions. As the effect of $\mathrm{pH}$ on the separation of lithium from aqueous solution by phosphorylated functional cellulose in the investigated $\mathrm{pH}$ range was minor, the sorption studies have been performed in the $\mathrm{pH}$ range of 56 , which is the original $\mathrm{pH}$ of the $\mathrm{LiCl}$ solution.

Beyond the initial $\mathrm{pH}$ of 2 , the final $\mathrm{pH}$ values were found as ca. 6.6 for all other initial $\mathrm{pH}(3,4$, 5, 6 and even 8, despite not reported). For better understanding the effect of $\mathrm{pH}$ on the adsorption of lithium by phosphorylated cellulose, the point of zero charge (PZC) value of this adsorbent was also determined as 6.75 , meaning that the adsorbent's surface was positively charged at a solution $\mathrm{pH}$ below 6.75. This causes competition between protons and lithium ions for adsorption locations, as well as the repulsion of lithium ions, resulting in the reduction of lithium adsorption. The lower the $\mathrm{pH}$ goes below $\mathrm{pH}_{\mathrm{PZC}}$, the greater the density of positive ions on the surface of phosphorylated cellulose will be, which in turn allows for less adsorption. This is confirmed by low lithium separation at a highly acidic $\mathrm{pH}$ of 2 .

\section{Effect of common ions}

Other cations, such as $\mathrm{Na}^{+}$and $\mathrm{K}^{+}$, present in the aqueous solution can compete with $\mathrm{Li}^{+}$for the same adsorption sites, obviously the coexistence of other ions inhibits the lithium adsorption and decreases the adsorption capacity. The effect of common ions is illustrated in Figure 10. Although the simultaneous presence of other cations in the solution reduced slightly the separation efficiency of $\mathrm{Li}$ from $94 \%$ to $87 \%$, compared to the efficiency achieved in the solution with only lithium under the same conditions, the overall adsorption capacity of the phosphorylated functional cellulose was improved. This phenomenon is due to a shift in the equilibrium towards the formation of the adsorbent-adsorbate complex with increasing concentration of the adsorbate.

Selectivity coefficients were calculated as follows: ${ }^{69}$

$\alpha_{A}^{B}=\frac{[A]^{a}}{[B]^{b}} \frac{[\bar{B}]^{b}}{[\bar{A}]^{a}}$

where brackets stand for concentrations in both liquid and solid phases, and the bar indicates the solid phase; $a$ is the selectivity coefficient of $\mathrm{B}^{+}$ over $\mathrm{A}^{+}$for the ion exchange reaction, and $a$ and $b$ are the valency of the ions.

Selectivity coefficients, $\alpha_{L i}^{N a}$ and $\alpha_{L i}^{R}$ of phosphorylated functional cellulose were calculated as 0.43 and 0.61 , respectively. Since those values are smaller than unity, among monovalent ions, it can be said that the synthesized adsorbent has more affinity towards lithium.

\section{Effect of initial concentration and temperature}

The effects of the initial lithium concentration and temperature on the uptake of lithium onto phosphorylated functional cellulose are depicted in Figure 11. An increase in initial concentration resulted in a corresponding increase in adsorption of lithium on the adsorbent. The rise in adsorption capacity with initial concentration can be conducted with the rise in the possibility of collisions between the adsorbent and the adsorbate. 


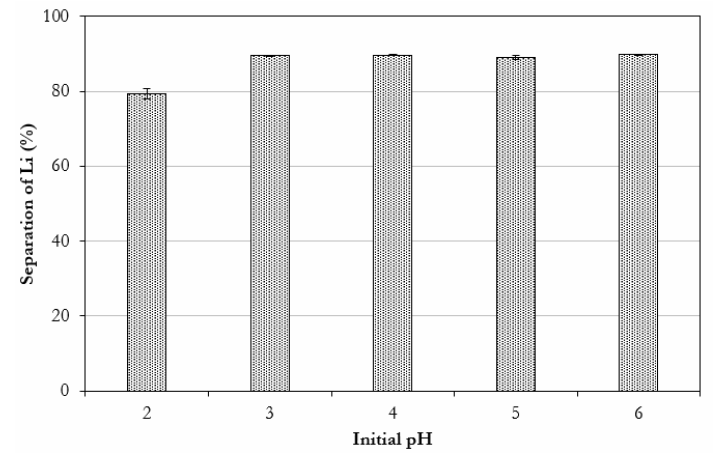

Figure 9: Effect of $\mathrm{pH}$ on the separation of lithium from aqueous solution by phosphorylated functional cellulose $\left(\mathrm{C}_{0}=10 \mathrm{mgL}^{-1}, \mathrm{~T}=25^{\circ} \mathrm{C}\right.$ and adsorbate dosage $=12.0 \mathrm{~g} / \mathrm{L})$

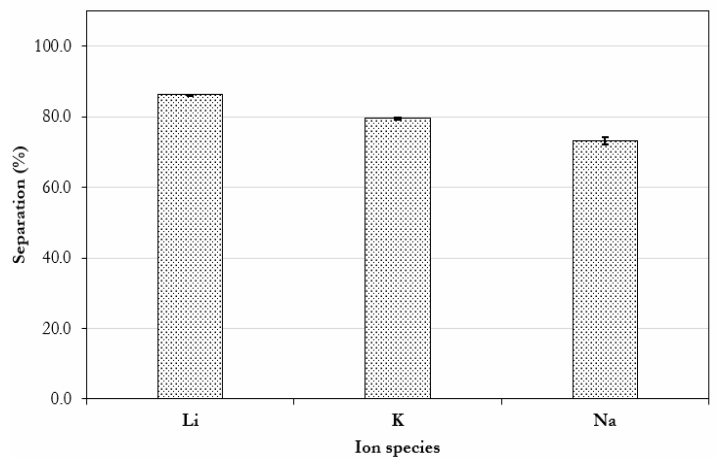

Figure 10: Separation efficiencies of coexisting ions by phosphorylated functional cellulose $\left(\mathrm{C}_{0}=10 \mathrm{mgL}\right.$ ${ }^{1}$ for each ion, $\mathrm{T}=25^{\circ} \mathrm{C}$ and adsorbate dosage $=12.0$ $\mathrm{g} / \mathrm{L})$

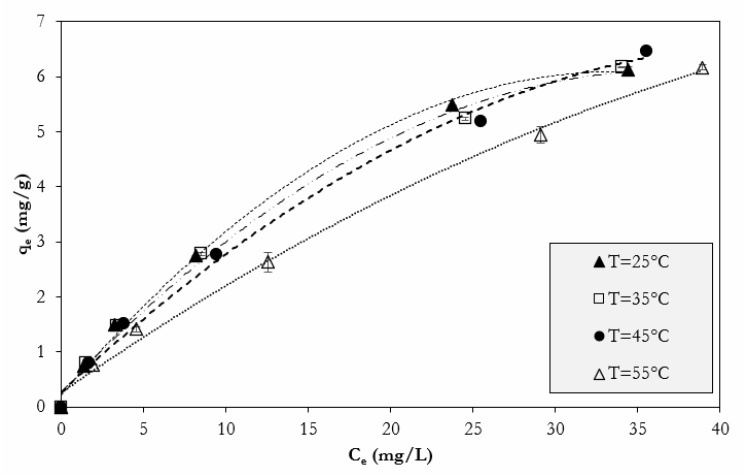

Figure 11: Adsorption isotherms for lithium at various temperatures using phosphorylated functional cellulose

The phenomenon is due to the acceleration of an originally driving force, i.e., concentration (basically chemical potential) difference, which may lead to enhanced adsorption. As temperature increased, the adsorption of lithium on phosphorylated functional cellulose decreased. This behavior indicates that the adsorption of lithium onto this adsorbent is an exothermic process, so that higher temperature will worsen the affinity of lithium ions to be adsorbed on the active sites of the adsorbent, as confirmed by the negative value of adsorption energy obtained from Van't Hoff's equation.

It is important to establish the most suitable correlation for the equilibrium curves to optimize the design of an adsorption system. ${ }^{70}$ Several isotherm models, such as Freundlich, Halsey, Langmuir, Redlich-Peterson and Temkin models, were used to describe the adsorption behavior and adsorption process of phosphorylated functional cellulose at various temperatures. The non-linear regression technique was applied by MATLAB $\AA$ software to determine the parameters and adequacy of these models. All the correlation coefficients, $\mathrm{R}^{2}$, sum of squares of error (SSE) and the constants obtained for the models are tabulated in Table 1.

Although it was difficult to distinguish, at moderately lower temperatures (i.e., $25^{\circ} \mathrm{C}$ and 35 ${ }^{\circ} \mathrm{C}$ ), the experimental data agreed better with the Langmuir isotherm, with a relatively higher $\mathrm{R}^{2}$ value of 0.997 and lower SSE value of 0.06. However, as the temperature increased to $45{ }^{\circ} \mathrm{C}$ and $55{ }^{\circ} \mathrm{C}$, the adsorption behavior was fitted better to the Freundlich isotherm model, according to the higher $\mathrm{R}^{2}$ of 0.999 and much lower SSE, ranging between 0.01-0.02.

Based on the Langmuir model assumption, monolayer maximum adsorption capacities $\left(\mathrm{Q}_{\max }\right)$ were determined as 9.60, 9.95, 11.26 and 12.60 $\mathrm{mg} / \mathrm{mg}$ at $25,35,45$ and $55{ }^{\circ} \mathrm{C}$, respectively. As the temperature increased, the Langmuir constant $\left(\mathrm{K}_{\mathrm{L}}\right)$ related to the affinity of binding sites decreased. All the dimensionless separation factors $\left(\mathrm{R}_{\mathrm{L}}\right)$ calculated for phosphorylated functional cellulose at various temperatures and initial lithium concentration were between 0 and 1 , indicating the shape of the isotherm as 
favorable for lithium adsorption. For example, as the initial concentration increased from 10 to 100 $\mathrm{mg} \mathrm{L}^{-1}$, the $\mathrm{R}_{\mathrm{L}}$ values decreased from 0.645 to 0.149 and from 0.746 to 0.225 at 25 and $55^{\circ} \mathrm{C}$, respectively. These results revealed that adsorption was more favorable at higher concentration and lower temperature.

The Freundlich isotherm was used for encompassing the exponential distribution of active sites and their energies and the surface heterogeneity. ${ }^{71}$ The value of $\mathrm{K}_{\mathrm{F}}$, which is a constant related to temperature and a measure for adsorption capacity, decreased from 0.7728 to 0.4498 as the temperature increased. Besides, a decrease in $n$ values from 1.6753 to 1.4026 with the temperature increase suggests a decreasing trend of the adsorption intensity. Because the rise in temperature caused a rise in the kinetic energy of lithium ions in the solution, hence, there occurred sharper competitions for the limited adsorption sites and strong repulsions among the lithium ions resulted in a decrease of adsorption intensity. The magnitude of the exponent $n$ also verifies the favorability of adsorption. The results show that lithium is favorably adsorbed by the phosphorylated functional cellulose due to the values of $n$ being greater than unity at all temperatures, which is in great agreement with the findings regarding to the $\mathrm{R}_{\mathrm{L}}$ values.

Table 1

Various isotherm model constants and correlation coefficients for adsorption of lithium on prepared phosphorylated cellulose at $25^{\circ} \mathrm{C}, 35^{\circ} \mathrm{C}, 45^{\circ} \mathrm{C}$ and $55^{\circ} \mathrm{C}$

\begin{tabular}{|c|c|c|c|c|}
\hline & $25^{\circ} \mathrm{C}$ & $35^{\circ} \mathrm{C}$ & $45^{\circ} \mathrm{C}$ & $55^{\circ} \mathrm{C}$ \\
\hline & \multicolumn{4}{|c|}{ Langmuir } \\
\hline $\mathrm{Q}_{\max }$ & $9.60 \mathrm{mg} / \mathrm{g}$ & $9.95 \mathrm{mg} / \mathrm{g}$ & $11.26 \mathrm{mg} / \mathrm{g}$ & $12.60 \mathrm{mg} / \mathrm{g}$ \\
\hline $\mathrm{K}_{\mathrm{L}}$ & $0.0529 \mathrm{~L} / \mathrm{mg}$ & $0.0466 \mathrm{~L} / \mathrm{mg}$ & $0.0359 \mathrm{~L} / \mathrm{mg}$ & $0.0305 \mathrm{~L} / \mathrm{mg}$ \\
\hline $\mathrm{R}^{2}$ & 0.997 & 0.997 & 0.995 & 0.993 \\
\hline \multirow[t]{2}{*}{ SSE } & 0.0619 & 0.0688 & 0.1086 & 0.1495 \\
\hline & \multicolumn{4}{|c|}{ Freundlich } \\
\hline $\mathrm{K}_{\mathrm{F}}$ & $0.7728 \mathrm{mg} / \mathrm{g}(\mathrm{L} / \mathrm{mg})^{1 / \mathrm{n}}$ & $0.7124 \mathrm{mg} / \mathrm{g}(\mathrm{L} / \mathrm{mg})^{1 / \mathrm{n}}$ & $0.6276 \mathrm{mg} / \mathrm{g}(\mathrm{L} / \mathrm{mg})^{1 / \mathrm{n}}$ & $0.4498 \mathrm{mg} / \mathrm{g}(\mathrm{L} / \mathrm{mg})^{1 / \mathrm{n}}$ \\
\hline $\mathrm{n}$ & 1.6753 & 1.6216 & 1.5311 & 1.4026 \\
\hline $\mathrm{R}^{2}$ & 0.990 & 0.998 & 0.999 & 0.999 \\
\hline \multirow[t]{2}{*}{ SSE } & 0.2356 & 0.0357 & 0.0117 & 0.0241 \\
\hline & \multicolumn{4}{|c|}{ Temkin } \\
\hline A & $0.856 \mathrm{~L} / \mathrm{mg}$ & $0.821 \mathrm{~L} / \mathrm{mg}$ & $0.6942 \mathrm{~L} / \mathrm{mg}$ & $0.5868 \mathrm{~L} / \mathrm{mg}$ \\
\hline B & 1.7426 & 1.732 & 1.8425 & 1.7559 \\
\hline $\mathrm{b}_{\mathrm{T}}$ & $1.422 \mathrm{~kJ} / \mathrm{mol}$ & $1.479 \mathrm{~kJ} / \mathrm{mol}$ & $1.436 \mathrm{~kJ} / \mathrm{mol}$ & $1.554 \mathrm{~kJ} / \mathrm{mol}$ \\
\hline $\mathrm{R}^{2}$ & 0.963 & 0.959 & 0.952 & 0.923 \\
\hline \multirow[t]{2}{*}{ SSE } & 0.8441 & 0.8946 & 1.1099 & 1.6321 \\
\hline & \multicolumn{4}{|c|}{ Redlich-Peterson } \\
\hline $\mathrm{K}_{\mathrm{RP}}$ & $0.505 \mathrm{~L} / \mathrm{mg}$ & $0.834 \mathrm{~L} / \mathrm{mg}$ & $1.1216 \mathrm{~L} / \mathrm{mg}$ & Not determined \\
\hline$\alpha$ & $0.0523(\mathrm{~L} / \mathrm{mg})^{\beta}$ & $0.254(\mathrm{~L} / \mathrm{mg})^{\beta}$ & $1.0296(\mathrm{~L} / \mathrm{mg})^{\beta}$ & \\
\hline$\beta$ & 1 & 0.591 & 0.458 & \\
\hline $\mathrm{R}^{2}$ & 0.997 & 1.000 & 1.000 & \\
\hline \multirow[t]{2}{*}{ SSE } & 0.0618 & 0.0055 & 0.0040 & \\
\hline & \multicolumn{4}{|c|}{ Halsey } \\
\hline $\mathrm{K}_{\mathrm{H}}$ & $1.5399 \mathrm{~L} / \mathrm{g}$ & $1.733 \mathrm{~L} / \mathrm{g}$ & $2.0408 \mathrm{~L} / \mathrm{g}$ & $3.067 \mathrm{~L} / \mathrm{g}$ \\
\hline $\mathrm{n}_{\mathrm{H}}$ & -1.6753 & -1.6216 & -1.5311 & -1.4026 \\
\hline $\mathrm{R}^{2}$ & 0.990 & 0.998 & 0.999 & 0.999 \\
\hline SSE & 0.2356 & 0.0357 & 0.0117 & 0.0241 \\
\hline
\end{tabular}

Despite having relatively lower $\mathrm{R}^{2}$ values, the Temkin model indicated that positive values of $b_{T}$ $(1.422,1.479,1.436$ and $1.554 \mathrm{~kJ} / \mathrm{mol})$ for all temperatures correspond to exothermic adsorption of lithium onto phosphorylated cellulose, where $\mathrm{b}_{\mathrm{T}}=\Delta \mathrm{Q}=-\Delta \mathrm{H}$. Given that those values are all less than $8 \mathrm{~kJ} / \mathrm{mol}$, the interactions between the adsorbate and the adsorbent are weak and therefore the adsorption mechanism taking place here is merely that of ion exchange. ${ }^{72}$

At $25{ }^{\circ} \mathrm{C}$, the R-P model transformed into the Langmuir isotherm, since $\beta$ was found to be 
exactly 1 . However, as the temperature increased, the value of $\beta$ decreased and lied between 0 and 1 . Lower $\beta$ values mean their isotherm curves are milder than those of the Langmuir isotherm equation, ${ }^{73}$ as can be seen in Figure 11.

The Halsey isotherm is valid for multilayer adsorption and the fitting of the experimental data to this model attest the heteroporous nature of the adsorbent. ${ }^{74}$ The high correlation coefficients for this model can be attributed to the heteroporous nature of phosphorylated cellulose, parallel to fitting more the Freundlich isotherm.

\section{Adsorption thermodynamics}

The thermodynamic parameters for phosphorylated functional cellulose at 298, 308, 318 and $328 \mathrm{~K}$ are listed in Table 2, indicating the effect of temperature on the adsorption process. The negative values of $\Delta G^{0}$ at all temperatures show that the adsorption of lithium onto the adsorbent was spontaneous and thermodynamically favorable, indicating increased randomness at the adsorbent-solution interface during the diffusion of lithium on the functional groups of cellulose. Therefore, the adsorbates have the tendency to stay in the stationary phase rather than in the mobile phase. The values of $\Delta \mathrm{H}^{0}$ and $\Delta \mathrm{S}^{0}$ were obtained from the slope and the intercept of the linear plot of $\ln \mathrm{K}_{\mathrm{e}}$ vs. 1/T respectively, as in Figure 12. $\Delta \mathrm{H}^{0}$ was found to be $-15.532 \mathrm{~kJ} / \mathrm{mol}$ and the negative value verified the exothermic nature of adsorption, which was also supported by the result that the adsorption of lithium decreased with the increase in temperature. The absolute value of $\Delta \mathrm{H}^{0}$ less than $40 \mathrm{~kJ} / \mathrm{mol}^{70}$ showed that there is an ionic interaction between the phosphate moiety and the $\mathrm{Li}$ ion. A negative value of $\Delta \mathrm{S}^{0}$ was attributed to a decrease in randomness at the solid-liquid interface during the adsorption of lithium.

\section{Adsorption kinetics}

Adsorption kinetics is useful to describe the rate of lithium uptake on the phosphorylated functional cellulose, which reveals the equilibrium time by means of the effect of contact time. The adsorption kinetic behavior of this adsorbent at various adsorbent dosage is depicted in Figure 13. The adsorption rate was found to be quite rapid initially, immediately slowing down and then reaching the equilibrium for lithium adsorption onto this adsorbent. An $80 \%$ lithium adsorption within 3 minutes with $5 \mathrm{~g} / \mathrm{L}$ of adsorbent dosage proved the quite fast kinetic nature of the adsorbent. Therefore, the adsorption kinetics analysis by some empirical kinetic models, such as pseudo-first order, pseudo-second order, intraparticle diffusion or Elovich model, could not be done because of difficulties in sampling less than 1 minute. Hence, observable data could not be collected to find the related rate constants or rate determining step proposed by Weber and Morris. ${ }^{75}$

\section{Desorption of lithium and regeneration of the adsorbent}

Desorption of $\mathrm{Li}$ from phosphorylated functional cellulose using $\mathrm{HCl}, \mathrm{NaCl}$ and $\mathrm{H}_{2} \mathrm{SO}_{4}$ at different concentrations $(0.5-2.0 \mathrm{M})$ is shown in Figure 14. The lowest desorption efficiency was observed as ca. $76 \%$ when $2.0 \mathrm{M} \mathrm{NaCl}$ solution was used, whereas a $99.5 \%$ desorption efficiency of lithium was achieved with $0.5 \mathrm{M} \mathrm{H}_{2} \mathrm{SO}_{4}$. On the other hand, the desorption of lithium was almost in close proximity and above $90 \%$ at all concentrations of $\mathrm{HCl}$. These results indicated that elution of lithium and the regeneration of the adsorbent can be easily done using acid solutions, especially with low concentration diprotic acids.

Table 2

Thermodynamic parameters for adsorption of lithium on phosphorylated functional cellulose

\begin{tabular}{cccc}
$\mathrm{T}(\mathrm{K})$ & $\Delta G^{\circ}(\mathrm{kJ} / \mathrm{mol})$ & $\Delta \mathrm{H}^{\circ}(\mathrm{kJ} / \mathrm{mol})$ & $\Delta \mathrm{S}^{\circ}(\mathrm{J} / \mathrm{mol} . \mathrm{K})$ \\
& & & \\
\hline 298 & -14.640 & & \\
308 & -14.806 & -15.532 & -2.776 \\
318 & -14.596 & & \\
328 & -14.610 & & \\
\hline
\end{tabular}


YAŞAR KEMAL RECEPOĞLU and ASLI YÜKSEL

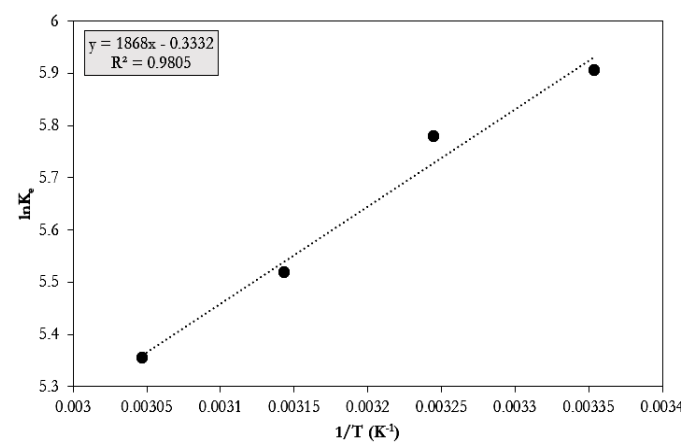

Figure 12: Plot of $\ln K_{e}$ vs. $1 / T$ for the sorption of lithium on phosphorylated functional cellulose

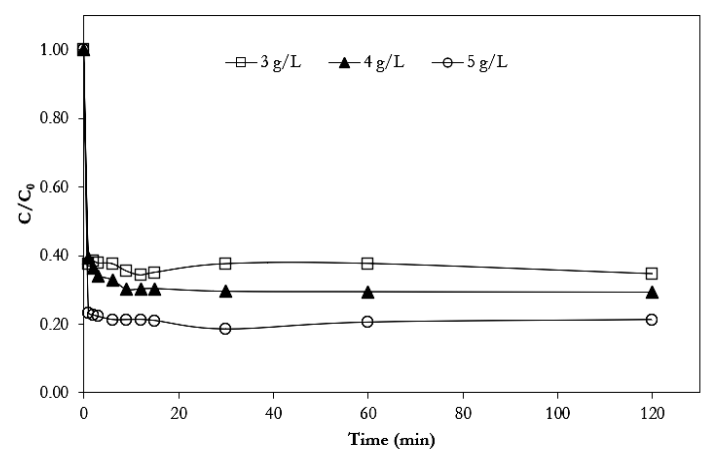

Figure 13: Effect of adsorbent dosage on adsorption kinetics using phosphorylated functional cellulose

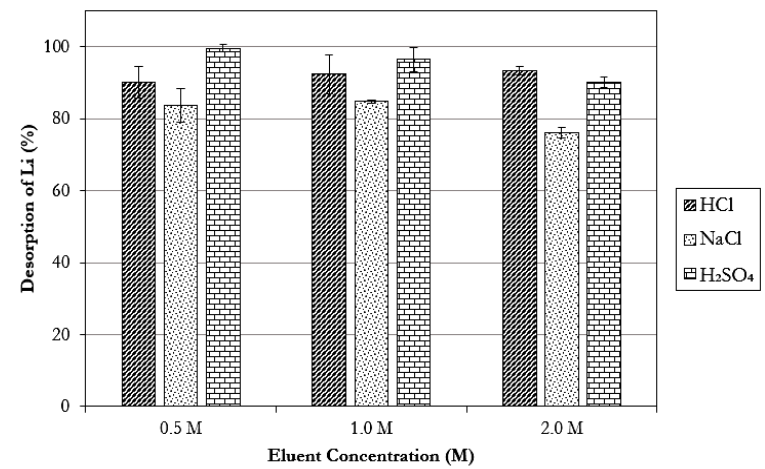

Figure 14: Desorption of Li from phosphorylated functional cellulose using different eluents at different concentrations

\section{CONCLUSION}

The present study showed that the synthesized cellulose-based phosphorylated functional material is a promising low-cost adsorbent to be utilized in the recovery of lithium from aqueous solutions. The adsorbent was synthesized by the reaction of cellulose with phosphorus acid in molten urea and characterized by SEM, EDX, FTIR, TGA and XPS to confirm its functionality. The results for the adsorption behavior of lithium on phosphorylated functional cellulose showed that the optimum adsorbent dosage to recover lithium from an initial concentration of $10 \mathrm{mg} / \mathrm{L}$ was $12.0 \mathrm{~g}$ adsorbent/L-solution, with a removal efficiency of ca. $94 \%$. There was no considerable influence of $\mathrm{pH}$ on the adsorption of lithium over the $\mathrm{pH}$ range studied. The simultaneous presence of other cations, such as $\mathrm{Na}^{+}$and $\mathrm{K}^{+}$, in the solution reduced slightly the separation efficiency of $\mathrm{Li}$ from $94 \%$ to $87 \%$, compared to the efficiency in the solution with only lithium under the same conditions. However, the adsorbent exhibited higher affinity towards lithium among others. The adsorption of lithium was found to increase with increasing initial concentration, but it decreased as the temperature increased due to the exothermic nature of lithium adsorption on this adsorbent.

A few isotherm models were applied. The results indicated that the adsorption isotherm models fitted the data in the order: Langmuir $\approx$ Freundlich $>$ Halsey $>$ Redlich-Peterson $>$ Temkin. The maximum lithium uptake capacity was estimated as $9.60 \mathrm{mg} / \mathrm{g}$ at $25^{\circ} \mathrm{C}$, which was higher than that of magnetic lithium ion imprinted polymer $(4.07 \mathrm{mg} / \mathrm{g})^{76}$ and ion-sieve manganese oxide $(8.5 \mathrm{mg} / \mathrm{g}){ }^{13}$ but comparable with commercially available Lewatit TP 260 resin $(13.65 \mathrm{mg} / \mathrm{g}){ }^{52}$ Thermodynamic analysis revealed that the adsorption of lithium on phosphorylated functional cellulose was spontaneous, exothermic, and with the tendency of decreased randomness. The kinetics of Li separation is quite fast and in three minutes it reached equilibrium. Moreover, the Li loaded phosphorylated functional cellulose can be easily regenerated with $0.5 \mathrm{M} \mathrm{H}_{2} \mathrm{SO}_{4}$ 
solution and the spent solution can be further evaporated to recover lithium from it.

As a future perspective, the output of the study provided an insight into the possibility of obtaining promising low-cost adsorbents from various lignocellulosic biomass wastes, which may have high cellulose content, and opens the way to lithium recovery from real water sources, such as geothermal water. The studies are in progress and will be published in the near future.

ACKNOWLEDGEMENTS: The authors greatly acknowledge Assoc. Prof. Dr. Özgür Arar at Ege University, Department of Chemistry for his kind support. In addition, we would like to thank "Center for Materials Research" for characterization analyses and "Environmental Research and Development Center" for ICP-OES analyses at Izmir Institute of Technology Integrated Research Center.

This study was financially supported through the projects of both The Scientific and Technological Research Council of Turkey-TUBITAK (Project No. 219M219) and Izmir Institute of Technology Scientific Research Projects Coordination Unit (Project No. 2019IYTE0178).

$\begin{array}{lll}\text { Abbreviations } & & \\ \text { EDX } & \text { Energy } \quad \text { Dispersive } & \text { X-Ray } \\ \text { Analysis } & & \\ \text { FTIR } & \text { Fourier-Transform } & \text { Infrared } \\ \text { Spectroscopy } & & \\ \text { ICP-OES } & \text { Inductively Coupled } & \text { Plasma- } \\ \text { Optical Emission Spectrometry } & \\ \text { SEM } & \text { Scanning Electron Microscopy } \\ \text { TGA } & \text { Thermogravimetric Analysis } \\ \text { XPS } & \text { X-ray } & \text { Photoelectron } \\ \text { Spectroscopy } & & \end{array}$

\section{REFERENCES}

1 X. Xu, Y. Chen, P. Wan, K. Gasem, K. Wang et al., Prog. Mater. Sci., 84, 276 (2016), https://doi.org/10.1016/j.pmatsci.2016.09.004

2 S. Reichel, T. Aubel, A. Patzig, E. Janneck and M. Martin, Miner. Eng., 106, 18 (2017), https://doi.org/10.1016/j.mineng.2017.02.012

3 M. Singh, J. Kaiser and H. Hahn, J. Electroanal. Chem., $\quad \mathbf{7 8 2}, \quad 245 \quad$ (2016), https://doi.org/10.1016/j.jelechem.2016.10.040

4 J. Park, H. Sato, S. Nishihama and K. Yoshizuka, Solvent Extr. Ion Exch., 30, 398 (2012), https://doi.org/10.1080/07366299.2012.687165

5 Q. Yu, K. Sasaki and T. Hirajima, J. Hazard. Mater., $\quad \mathbf{2 6 2}, \quad 38 \quad$ (2013), https://doi.org/10.1016/j.jhazmat.2013.08.027
6 B. Swain, Sep. Purif. Technol., 172, 388 (2017), https://doi.org/10.1016/j.seppur.2016.08.031

7 V. D. Dang and M. Steinberg, Energy, 3, 325 (1978), https://doi.org/10.1016/0360-5442(78)90029-4

8 C. Shi, Y. Jing, J. Xiao, X. Wang, Y. Yao et al., Sep. Purif. Technol., 172, 473 (2017), https://doi.org/10.1016/j.seppur.2016.08.034

9 J. A. Epstein, E. M. Feist, J. Zmora and Y. Marcus, Hydrometallurgy, $\quad$ 6, $269 \quad$ (1981), https://doi.org/10.1016/0304-386X(81)90044-X

10 K. Yanagase, T. Yoshinaga, K. Kawano and T. Matsuoka, Bull. Chem. Soc. Jpn., 56, 2490 (1983), https://doi.org/10.1246/bcsj.56.2490

11 A. Iizuka, Y. Yamashita, H. Nagasawa, A. Yamasaki and Y. Yanagisawa, Sep. Purif. Technol., 113, 33 (2013), https://doi.org/10.1016/j.seppur.2013.04.014

12 A. Somrani, A. H. Hamzaoui and M. Pontie, Desalination, $\quad 317, \quad 184 \quad$ (2013), https://doi.org/10.1016/j.desal.2013.03.009

13 Y. Miyai, K. Ooi and S. Katoh, Sep. Sci. Technol., 23, 179

(1988),

https://doi.org/10.1080/01496398808057641

14 R. Chitrakar, H. Kanoh, Y. Miyai and K. Ooi, Ind. Eng. Chem. Res., 40, 2054 (2001), https://doi.org/10.1021/ie000911h

15 K. Yoshizuka, K. Fukui and K. Inoue, Ars

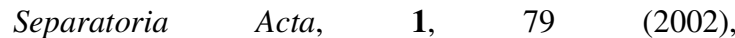
http://yadda.icm.edu.pl/yadda/element/bwmeta1.eleme nt.baztech-article-BATA-0007-0006

16 A. Kitajou, T. Suzuki, S. Nishihama and K. Yoshizuka, Ars Separatoria Acta, 2, 97 (2003), http://yadda.icm.edu.pl/baztech/element/bwmeta1.elem ent.baztech-article-BATA-0007-0022

17 A. Kitajou, M. Holba, T. Suzuki, S. Nishihama and K. Yoshizuka, J. Ion Exch., 16, 49 (2005), https://www.jstage.jst.go.jp/article/jaie1990/16/1/16_1 _49/_article

${ }_{18}$ A. Kitajou, Y. Suzuka, S. Nishihama, T. Suzuki and K. Yoshizuka, J. Ion Exch., 17, 7 (2006), https://www.jstage.jst.go.jp/article/jaie1990/17/1/17_1 _7/_article/-char/en

19 R. Chitrakar, H. Kanoh, Y. Miyai and K. Ooi, J. Solid State Chem., 163, 1 (2002), https://doi.org/10.1006/jssc.2001.9403

20 R. Chitrakar, S. Kasaishi, A. Umeno, K. Sakane, N. Takagi et al., J. Solid State Chem., 169, 35 (2002), https://doi.org/10.1016/S0022-4596(02)00014-2

21 Y. S. Kim, K. S. No, K. S. Chung, J. C. Lee and K. Ooi, Mater. Lett., 57, $4140 \quad$ (2003), https://doi.org/10.1016/S0167-577X(03)00279-9

22 S. Nishihama, K. Onishi and K. Yoshizuka, Solvent Extr. Ion Exch., 29, $421 \quad$ (2011), https://doi.org/10.1080/07366299.2011.573435

23 L. Li, W. Qu, F. Liu, T. Zhao, X. Zhang et al., Appl. Surf. Sci., 315, 59 (2014), https://doi.org/10.1016/j.apsusc.2014.07.090

${ }_{24}$ Y. K. Recepoğlu, N. Kabay, İ. Y1lmaz-Ipek, M. Arda, K. Yoshizuka et al., Solvent Extr. Ion Exch., 35, 
221

https://doi.org/10.1080/07366299.2017.1319235

(2017),

25 Y. K. Recepoğlu, N. Kabay, K. Yoshizuka, S. Nishihama, İ. Y1lmaz-Ipek et al., Solvent Extr. Ion Exch., 36, 499 (2018), https://doi.org/10.1080/07366299.2018.1529232

26 Y. K. Recepoğlu, N. Kabay, I. Y. Ipek, M. Arda, M. Yüksel et al., Desalination, 437, 1 (2018), https://doi.org/10.1016/j.desal.2018.02.022

27 D. Sengupta and R.W. Pike, "Chemicals from Biomass. Integrating Bioprocesses into Chemical Production Complexes for Sustainable Development", CRC Press, Taylor \& Francis Group, 2012

28 D. M. Suflet, G. C. Chitanu and V. I. Popa, React. Funct. Polym., 66, $1240 \quad$ (2006), https://doi.org/10.1016/j.reactfunctpolym.2006.03.006

${ }_{29}$ Y. Zhou, M. Zhang, X. Wang, Q. Huang, Y. Min et al., Ind. Eng. Chem. Res., 53, 5498 (2014), https://doi.org/10.1021/ie404135y

${ }^{30}$ X. Yue, J. Huang, F. Jiang, H. Lin and Y. Chen, J. Eng. Fiber. Fabr., 14, 1 (2019), https://doi.org/10.1177/1558925019828194

31 K. S. Low, C. K. Lee and S. M. Mak, Wood Sci. Technol., 38, 629 (2004), https://doi.org/10.1007/s00226-003-0201-9

32 L. V. A. Gurgel, O. K. Júnior, R. P. de F. Gil and L. F. Gil, Bioresour. Technol., 99, 3077 (2008), https://doi.org/10.1016/j.biortech.2007.05.072

33 B. Belhalfaoui, A. Aziz, E. H. Elandaloussi, M. S. Ouali and L. C. De Ménorval, J. Hazard. Mater., 169, 831 https://doi.org/10.1016/j.jhazmat.2009.04.021 34 L. V. A. Gurgel and L. F. Gil, Carbohyd. Polym., 77, 142

(2009),

https://doi.org/10.1016/j.carbpol.2008.12.014

35 L. V. A. Gurgel, J. C. Perin de Melo, J. C. de Lena and L. F. Gil, Bioresour. Technol., 100, 3214 (2009), https://doi.org/10.1016/j.biortech.2009.01.068

36 J. C. P. Melo, E. C. Silva Filho, S. A. A. Santana and C. Airoldi, Thermochim. Acta, 524, 29 (2011), https://doi.org/10.1016/j.tca.2011.06.007

37 B. Pangeni, H. Paudyal, K. Inoue, H. Kawakita, K. Ohto et al., Cellulose, 19, 381 (2012), https://doi.org/10.1007/s10570-011-9628-6

38 C. H. Zhou, D. Zhang, D. S. Tong, L. M. Wu, W. H. Yu et al., Chem. Eng. J., 209, 223 (2012), https://doi.org/10.1016/j.cej.2012.07.107

${ }_{39}$ Y. Zhou, Q. Jin, X. Hu, Q. Zhang and T. Ma, J. Mater. Sci., 47, $5019 \quad$ (2012), https://doi.org/10.1007/s10853-012-6378-2

${ }^{40}$ S. Hokkanen, E. Repo and M. Sillanpää, Chem. Eng. $\quad J$., $\quad \mathbf{2 2 3}, \quad 40 \quad$ (2013), https://doi.org/10.1016/j.cej.2013.02.054

41 L. H. Velazquez-Jimenez, A. Pavlick and J. R. Rangel-Mendez, Ind. Crop. Prod., 43, 200 (2013), https://doi.org/10.1016/j.indcrop.2012.06.049

42 X. Yu, S. Tong, M. Ge, L. Wu, J. Zuo et al., J. Environ. Sci. (China), 25, 933 (2013), https://doi.org/10.1016/S1001-0742(12)60145-4
43 A. Kardam, K. R. Raj, S. Srivastava and M. M. Srivastava, Clean Technol. Environ. Policy, 16, 385 (2014), https://doi.org/10.1007/s10098-013-0634-2

44 D. Belosinschi, B. Chabot and F. Brouillette, BioResources, 7, $902 \quad$ (2012), https://ojs.cnr.ncsu.edu/index.php/BioRes/article/view/ BioRes_07_1_0902_Belosinschi_CB_Release_Paper_ Phosphate_Esters_Silicone/0

45 Y. Shi, D. Belosinschi, F. Brouillette, A. Belfkira and B. Chabot, Carbohyd. Polym., 106, 121 (2014), https://doi.org/10.1016/j.carbpol.2014.01.070

46 N. Illy, M. Fache, R. Ménard, C. Negrell, S. Caillol et al., Polym. Chem., 6, 6257 (2015), https://doi.org/10.1039/c5py00812c

47 T. Sakaguchi, T. Horikoshi and A. Nakajima, Agric. Biol. Chem., 45, $2191 \quad$ (1981), https://doi.org/10.1080/00021369.1981.10864862

${ }^{48}$ T. Oshima, K. Kondo, K. Ohto, K. Inoue and Y. Baba, React. Funct. Polym., 68, 376 (2008), https://doi.org/10.1016/j.reactfunctpolym.2007.07.046

${ }^{49}$ I. Chen, C. Xu, J. Peng, D. Han, S. Liu et al., Molecules, 24, 2762 (2019), https://doi.org/10.3390/molecules24152762

50 C. Xu, T. Yu, J. Peng, L. Zhao, J. Li et al., Quantum Beam Sci., 4, 6 (2020), https://doi.org/10.3390/qubs4010006

51 L. Tang, S. Huang, Y. Wang, D. Liang, Y. Li et al., ACS Appl. Mater. Interfaces, 12, 9775 (2020), https://doi.org/10.1021/acsami.9b21612

52 A. Çiçek, O. Yilmaz and Ö. Arar, J. Serbian Chem. Soc., $\quad \mathbf{8 3}, \quad 1059 \quad$ (2018), https://doi.org/10.2298/JSC170930020C

53 K. Yabusaki, Google Patents September 28, 2010, Patent No: US 7,803,937 B2, (2010)

54 O. Hamdaoui and E. Naffrechoux, J. Hazard. Mater., $\quad$ 147, $381 \quad$ (2007), https://doi.org/10.1016/j.jhazmat.2007.01.021

55 B. Ismail, S.T. Hussain and S. Akram, Chem. Eng. J., 219, $395 \quad$ (2013), https://doi.org/10.1016/j.cej.2013.01.034

56 I. Langmuir, J. Am. Chem. Soc., 38, 2221 (1916), https://doi.org/10.1021/ja02268a002

57 B. H. Hameed, I. A. W. Tan and A. L. Ahmad, Chem. Eng. J., 144, 235 (2008), https://doi.org/10.1016/j.cej.2008.01.028

58 H. Freundlich, Zeitschrift Für Phys. Chemie, 57, 385 (1907), https://doi.org/10.1515/zpch-1907-5723

59 O. Redlich and D. L. Peterson, J. Phys. Chem., 63, 1024 (1959), https://doi.org/10.1021/j150576a611

60 M. I. Tempkin and V. Pyzhev, Acta Phys. Chim. USSR, 12, 327 (1940)

61 Y. Khambhaty, K. Mody, S. Basha and B. Jha, Chem. Eng. J., 145, 489 (2009), https://doi.org/10.1016/j.cej.2008.05.002

62 G. Halsey, J. Chem. Phys., 16, 931 (1948), https://doi.org/10.1063/1.1746689

${ }^{63}$ H. Lin, S. Han, Y. Dong and Y. He, Appl. Surf. Sci., 412, 152 (2017), https://doi.org/10.1016/j.apsusc.2017.03.061 
64 E. C. Lima, A. Hosseini-Bandegharaei, J. C. Moreno-Piraján and I. Anastopoulos, J. Mol. Liq., 273, 425 (2019),

https://doi.org/10.1016/j.molliq.2018.10.048

65 G. Socrates, "Infrared and Raman Characteristic Group Frequencies: Tables and Charts", John Wiley \& Sons, 2004

66 N. K. Luneva and T. I. Ezovitova, Russ. J. Appl. Chem. 87 1558 (2014), https://doi.org/10.1134/S1070427214100243

67 D. Aoki and Y. Nishio, Cellulose, 17, 963 (2010), https://doi.org/10.1007/s10570-010-9440-8

68 J. Ulatowska, I. Polowczyk, A. Bastrzyk, T. Koźlecki and W. Sawiński, Sep. Sci. Technol., 55, 2149 (2019),

https://doi.org/10.1080/01496395.2019.1612434

${ }^{69}$ F. G. Helfferich, "Ion Exchange", McGraw-Hill, New York, (1962)

70 I. Yilmaz Ipek, Sep. Sci. Technol., 49, 2358
(2014), https://doi.org/10.1080/01496395.2014.915415

71 T. S. Jamil, T. A. Gad-Allah, H. S. Ibrahim and T. S. Saleh, Solid State Sci., 13, 198 (2011), https://doi.org/10.1016/j.solidstatesciences.2010.11.01 4

72 J. Ghogomu, Br. J. Appl. Sci. Technol., 3, 942 (2013), https://doi.org/10.9734/bjast/2014/4384

73 F. C. Wu, B. L. Liu, K. T. Wu and R. L. Tseng, Chem. Eng. J., 162, $21 \quad$ (2010), https://doi.org/10.1016/j.cej.2010.03.006

74 N. Ayawei, A. N. Ebelegi and D. Wankasi, J. Chem., 2017, 1 (2017), https://doi.org/10.1155/2017/3039817

75 W. J. Weber and J. C. Morris, J. Sanit. Eng. Div., 89, 31 (1963)

76 X. Luo, B. Guo, J. Luo, F. Deng, S. Zhang et al., ACS Sustain. Chem. Eng., 3, 460 (2015), https://doi.org/10.1021/sc500659h 